ABA initiators was higher than for TNFi initiators due to the higher proportion of pts continuing $A B A$ after 6 months. ABA treatment resulted in lower hospitalization costs. The cost per QALY for ABA (vs TNFi) was $£$ 8667. An intervention with an ICER of less than $£ 30,000$ per QALY gained is generally considered to be cost effective in the UK. In a sensitivity analysis, in which the annual cost of TNFi was assumed to be the same as a biosimilar agent ( $£ 7829$ ), the ICER increased to $£$ 25,660 .

Conclusions: Based on real-world data, abatacept is a cost-effective alternative to TNFi in an ACPA+ pt with RA. The increased treatment costs of abatacept are offset by the gain in benefits (QALYs) from higher CDAl reductions with abatacept. References:

[1] van der Helm-van Mil AHM, et al. Arthritis Res Ther 2005;7:R949-58.

[2] Harrold LR, et al. Ann Rheum Dis 2016;75(Suppl 2):505-6.

[3] Malottki K, et al. Health Technol Assess 2011;15:1-278.

[4] Stevenson MD, et al. Health Technol Assess 2016;20:1-610.

Disclosure of Interest: S. Johal Consultant for: PAREXEL Access Consulting received a Consultancy fee to support the analysis, Employee of: HERON Commercialization, E. Alemao Shareholder of: Bristol-Myers Squibb, Employee of: Bristol-Myers Squibb

DOI: 10.1136/annrheumdis-2017-eular.3436

\section{THU0726-HPR WHAT CHARACTERISES PATIENTS REFERRED FOR SURGICAL CONSULTATION DUE TO CARPOMETACARPAL OSTEOARTHRITIS?}

E.M.H. Gravas ${ }^{1}$, R. Nossum ${ }^{2}$, R.E.M. Eide ${ }^{3}$, A. Klokkereide ${ }^{4}$, K.H. Matre ${ }^{3}$, M. Olsen ${ }^{4}$, S. Darre ${ }^{2}$, O. Andreassen ${ }^{1}$, N. Osteras ${ }^{1}$, I. Kjeken ${ }^{1}$.

${ }^{1}$ Diakonhjemmet Hospital, Oslo; ${ }^{2}$ St.Olavs Hospital, Trondheim; ${ }^{3}$ Haukeland University Hospital, Bergen; ${ }^{4}$ Haugesund Rheumatism Hospital, Haugesund, Norway

Background: Carpometacarpal osteoarthritis (CMC-OA) is a common joint condition, with a prevalence of $13 \%$ in people aged 41 to 50 years, increasing to $68 \%$ in people between 71 and 80 years. In the absence of diseasemodifying interventions, non-pharmacological approaches are considered as core treatments for hand OA, while surgery is recommended for those with severe CMC-OA.

Objectives: To describe function and previous treatment in patients referred for surgical consultation due to CMC-OA.

Methods: Individuals referred for surgical consultation due to their CMC-OA at three Norwegian departments of rheumatology were invited to participate. Those who agreed attended a clinical assessment and reported their symptoms, disability and function using validated outcome measures including the Quick-Dash (0-100, $0=$ no disability) and the MAPHand (1-4, 1=no limitations)

Results: A total of 180 patients (mean age 63 , range: 45 to $82 ; 79 \%$ women) were included. Thirty-six percent were referred for right hand, $43 \%$ for left hand, and $21 \%$ for bilateral surgery. Concerning previous treatment for hand OA, $21 \%$ ( $78 \%$ women) had received hand surgery, $22 \%$ ( $81 \%$ women) physical or occupational therapy, and $11 \%$ (95\% women) had consulted a rheumatologist. Women consistently reported higher pain levels compared to men, had more finger joints with bony enlargements and significantly lower grip and pinch strength in both hands (Table). They also reported significantly more disability and activity limitations at Quick Dash; 38.6 versus $30.4,(p=0.006)$ and MAPHand; 2.0 versus $1.7(p<0.001)$, for women and men, respectively. However, for finger range of motion, men had slightly more flexion deficit and less palmar abduction in their left hand compared to women.

Conclusions: Among patients referred for surgical consultation due to CMC-OA, women self-reported lower hand function and scored poorer than men in observer based assessments. Even if conservative treatment is recommended before referral for surgery, only a few participants had received such treatment for their hand $\mathrm{OA}$.

Disclosure of Interest: None declared

DOI: 10.1136/annrheumdis-2017-eular.3662

\section{THU0727-HPR BLENDED INTERVENTIONS FOR FATIGUE SELF-MANAGEMENT: IS THIS THE WAY PATIENTS AND PROFESSIONALS LIKE TO GO?}

C. Bode ${ }^{1}$, E. Taal ${ }^{1}$, H. Vonkeman ${ }^{2}$, F. Ben Allouch ${ }^{1}$, K. Hohl ${ }^{1} .{ }^{1}$ Psychology, Health \& Technology, University Twente: ${ }^{2}$ Rheumatology, Medisch Spectrum Twente, Enschede, Netherlands

Background: Blended care, the integration of online and face-to-face care, promises to combine the best of two worlds.

Objectives: To explore the attitudes and needs concerning blended care of two key stakeholders: health professionals and patients.

Methods: Rheumatologists (8) and specialized nurses (5) were recruited in a Dutch hospital and patients with an inflammatory rheumatic disease (10) were recruited via flyers in hospitals and patient organizations in Germany. A semi-structured interview scheme was used to explore knowledge, experiences, needs and perceived (dis)advantages of a blended care format for fatigue self-management. Transcribed verbal data were coded with hierarchical coding schemes.

Results: Perspective of professionals: Blended care matches needs for psychosocial interventions in medical settings, has a patient-friendly and flexible format, reflects the active role of patients and can easily be imbedded in standard care. Reported barriers were low education and skills in technology use in patients, the lack of proven and safe interventions and costs for development/ implementation. Patient perspective: Patients expected better communication, time saving and improvement of autonomy in self-management. They were concerned about loss of personal contact and in general, patients were very critical regarding online activities, privacy risks and guaranteed quality of eHealth products.

Conclusions: Health professionals and patients differ in their attitudes towards blended care. Professionals are better informed and have a more positive attitude, whereas patients' attitudes towards blended care are mainly driven by their reservations towards the reliability and safety of the internet in general. Results will be discussed on the background of attitudes towards eHealth in different countries.

Disclosure of Interest: None declared

DOI: 10.1136/annrheumdis-2017-eular.6838

\section{THU0728-HPR COMPARISON OF THE EFFECTIVENESS OF FUNCTIONAL AND NIGHT SPLINT FOR RHIZARTHROSIS: ONE-YEAR FOLLOW-UP OF A CONTROLLED, RANDOMIZED, BLINDED CLINICAL TRIAL}

F.C. Silva, S.M.M. Adolph, R.V.T. da Silva, J. Natour. Department of rheumatology, Federal university of São Paulo, São Paulo, Brazil

Background: Rhizarthrosis is an inflammatory degenerative joint disease affecting the trapeziometacarpal joint. The main symptom is pain, leading to difficulty with hand functions and reduced quality of life. Two randomized controlled trials found in the literature reported similar findings in terms of pain reduction and improved hand function with the use of a short orthosis for rhizarthrosis; one of the trials showed the benefits when the device was used for daytime function while the other showed the benefits when the orthosis was used during nighttime rest.

Objectives: To compare the effectiveness of functional (daytime) and night splint (Figure 1) in reducing pain and improving functionality in patients with rhizarthrosis.

Methods: A controlled, randomized, blinded clinical trial with sixty patients diagnosed with rhizarthrosis. The patients were assessed by a blinded assessor at the beginning of the treatment and after 45, 90, 180 and 360 days the following variables were evaluated: pain at the base of the thumb using a a numerical pain scale; thumb range of motion measured using a goniometer; grip strength evaluated by a hydraulic hand dynamometer; pinch strength using the pinch gage; hand dexterity evaluated with the pick-up test; function evaluated by the Brazilian version of the AUSCAN LK 3.01 Hand Osteoarthritis Index, the Cochin Hand Function Scale, the Michigan Hand Outcomes Questionnaire and a Likert-type scale. The Hand Outcomes Questionnaire, Cochin Scale and Michigan Questionnaire were used to assess hand function and patient satisfaction using a Likert scale.

Results: Most of the variables analyzed, including patient characteristics such

Abstract THU0726-HPR - Table 1. Hand function

\begin{tabular}{|c|c|c|c|c|c|c|}
\hline & \multicolumn{2}{|c|}{ Right hand } & \multirow[t]{2}{*}{$p$-value } & \multicolumn{2}{|c|}{ Left hand } & \multirow[t]{2}{*}{$\mathrm{p}$-value } \\
\hline & Women & Men & & Women & Men & \\
\hline Proportion with normal max grip strength ${ }^{a}$, \% (SD) & $65,7(27,6)$ & $90,9(26,1)$ & $<0,001$ & $64,0(26,3)$ & $83,5(21,2)$ & $<0,001$ \\
\hline Proportion with normal max pinch strength ${ }^{\mathrm{a}}, \%$ (SD) & $66,2(28,8)$ & $73,6(28,3)$ & $<0,001$ & $66,8(25,8)$ & $71,5(29,0)$ & $<0,001$ \\
\hline Pain at rest ${ }^{b}$, mean (SD) & $2,3(2,2)$ & $1,7(1,8)$ & 0,10 & $2,8(2,6)$ & $2,3(2,1)$ & 0,23 \\
\hline Pain following grip strength assessment ${ }^{b}$,mean (SD) & $2,7(2,5)$ & $2,4(2,9)$ & 0,60 & $2,6(2,3)$ & $2,5(2,4)$ & 0,92 \\
\hline Pain following pinch strength assessment ${ }^{b}$, mean (SD) & $2,9(2,7)$ & $2,7(3,0)$ & 0,67 & $3,1(2,8)$ & $3,1(2,7)$ & 0,98 \\
\hline Total flexion deficit $(\mathrm{mm})$, mean (SD) & $11,2(30,5)$ & $8,0(24,4)$ & 0,56 & $10,4(27,8)$ & $10,7(33,6)$ & 0,96 \\
\hline
\end{tabular}

a Measured in Newton using the Grippit. ${ }^{\mathrm{b} N u m e r i c}$ rating scale (NRS): $0-10,0=$ no pain. ${ }^{\mathrm{C}}$ Measured in degrees using the Pollexograph. 